\title{
Suicidal ideation, psychopathology and associated factors among HIV-infected adults in Indonesia
}

\author{
Youdiil Ophinni ${ }^{1}$, Adrian$^{2}$, Kristiana Siste ${ }^{2^{*}} \mathbb{D}$, Martina Wiwie ${ }^{2}$, Gina Anindyajati ${ }^{2}$, Enjeline Hanafi ${ }^{2}$,
} Reza Damayanti ${ }^{2}$ and Yoshitake Hayashi ${ }^{1}$

\begin{abstract}
Background: Suicidal behavior is a prevalent psychiatric emergency in HIV-infected adults. Detection of suicidal ideation is important in planning early psychiatric intervention and optimizing HIV/AIDS management. Characterization of suicidal ideation among HIV-infected adults is crucial; however, practically there is no data in Indonesia, the country with the second largest burden of HIV/AIDS epidemic in Asia. This study aims to identify suicidal ideation and analyze the associated psychopathology and determining factors among HIV-infected adults in Indonesia.

Methods: An observational cross-sectional study was conducted among HIV-infected adults aged 18-65 years old receiving antiretroviral therapy (ART). Measurement using Symptom Checklist-90 (SCL-90) was performed to assess the existing psychopathology. Firth's penalized logistic regression analysis was performed to identify factors associated with suicidal ideation.

Results: A total of 86 subjects were recruited. Most subjects were male (65.1\%), median age was 35 years, and median latest CD4 count was 463 cells/ $\mu$ l. Lifetime suicidal ideation was identified in 20 subjects (23.3\%). Mean SCL-90 T-score for depressive and anxiety symptoms were both significantly higher among subjects with suicidal ideation $(M=60.75$, $S D=12.0, p=0.000$ and $M=57.9, S D=2.8, p=0.001$, respectively) compared to those without. Bivariate analyses showed that lifetime suicidal ideation was associated with depressive and anxiety symptoms, non-marital status, CD4 count $<500$ cells $/ \mu$, and efavirenz use. Multivariate analysis identified that a single-point increase in SCL-90 depression symptoms score (AOR 1.16,95\% Cl 4.5-123.6, $p=0.000$ ) and efavirenz use (AOR 5.00, 95\% Cl 1.02-24.6, $p=0.048$ ) were significant independent factors related to suicidal ideation.

Conclusion: Suicidal ideation is commonly found among Indonesian HIV-infected adults on ART. Depressive symptoms and efavirenz use are independent factors related to the presence of suicidal ideation. Thus, early screening of psychopathology as well as substitution of efavirenz with other ART regiment are recommended to prevent suicide and improve HIV/AIDS management outcome.
\end{abstract}

Keywords: Depression, HIV/AIDS, Psychopathology, Suicidal behavior, Efavirenz

\footnotetext{
* Correspondence: ksiste@yahoo.com

2Department of Psychiatry, Faculty of Medicine, Universitas Indonesia, 71

Diponegoro, Central Jakarta, DKI, Jakarta, Indonesia

Full list of author information is available at the end of the article
}

(c) The Author(s). 2020 Open Access This article is licensed under a Creative Commons Attribution 4.0 International License, which permits use, sharing, adaptation, distribution and reproduction in any medium or format, as long as you give appropriate credit to the original author(s) and the source, provide a link to the Creative Commons licence, and indicate if changes were made. The images or other third party material in this article are included in the article's Creative Commons licence, unless indicated otherwise in a credit line to the material. If material is not included in the article's Creative Commons licence and your intended use is not permitted by statutory regulation or exceeds the permitted use, you will need to obtain permission directly from the copyright holder. To view a copy of this licence, visit http://creativecommons.org/licenses/by/4.0/. The Creative Commons Public Domain Dedication waiver (http://creativecommons.org/publicdomain/zero/1.0/) applies to the data made available in this article, unless otherwise stated in a credit line to the data. 


\section{Background}

Suicide is one of the leading causes of death worldwide. In 2018, World Health Organization (WHO) estimated that almost 800,000 people die due to suicide annually, $79 \%$ of which occurred in low- and middle-income countries (LMICs) [1, 2]. Phases of suicidal behavior can be divided into suicidal ideation, plans, and attempt $[3,4]$. Centers for Disease Control and Prevention (CDC) defines suicide as death caused by self-directed harmful behavior with an intention of dying as a result, while suicidal ideation is defined as having a thought of or considering suicide $[3,5,6]$. WHO surveyed 21 countries in 2001-2007 and reported lifetime prevalence of suicidal ideation as 2.0 to $2.1 \%[7,8]$. The majority of individuals $(60 \%)$ who made a suicidal plan or attempt proceeded to do so within one year since the ideation onset $[3,7]$.

Suicidal behavior has been well characterized as a pervasive comorbidity among people living with HIV (PLHIV), which may represent the prevalence of mental disorders among PLHIV [9]. HIV infection may either directly disrupt central nervous system (CNS), associated with CNS-related opportunistic infections that defines acquired immune deficiency syndrome (AIDS), or might be accompanied by environmental issues negatively affecting mental health (e.g. substance use, socioeconomic burden, and stigma) [10-12]. All of these may lead to increased risk of psychopathology. Indeed, a 2018 study in UK showed that a higher proportion of PLHIV presented with depressive symptoms (27.0\% versus $10.5 \%)$ and anxiety (21.6\% versus 9.6\%) compared to demographically-matched HIV-negative group [13, 14]. Almost double of those numbers were reported in Asian countries, such as China (50.8\% of PLHIV showing depressive symptoms) and India (50\% and 25-36\% of PLHIV showing depressive and anxiety symptoms, respectively) [15-17]. Prevalence in LMICs was similarly high, but resource limitation further added difficulties to the situation, due to underdiagnosis of mental disorders, suboptimal access to treatment, and limited research-based knowledge [18, 19]. Subsequently, suicidal behavior was reported at an alarmingly high rate among PLHIV: $22.5 \%$ of PLHIV in Ethiopia showed suicidal ideation [20], increase in suicide rate due to HIV seropositive status was reported in South Africa (13.3 to 18.9\%) [21], and suicidal ideation was reported in as many as $45 \%$ of HIV-positive men who have sex with men (MSM) in India [22]. High suicidal burden among PLHIV has been consistently reported across countries, highlighting the urgency to monitor associated factors to suicidal ideation [23].

Notwithstanding the scarcity of studies in LMICs, distinct factors predictive of suicidal behavior have been well described [7, 18, 19]. HIV positive status, together with socioeconomic burden, poor social support, and perceived stigma, were found to be predictive of suicide attempt in South Africa [21]. In high-income countries
(HICs), socioeconomic factors are associated less strongly compared to the progression of HIV disease itself. In Switzerland, for example, lower cluster-of-differentiation4-expressing $\mathrm{T}$ cells (CD4 T cells) and advanced HIV/ AIDS stage were related to higher suicide rate among PLHIV [24]. In particular, antiretroviral therapy (ART) containing efavirenz as a non-nucleoside reverse transcriptase inhibitor (NNRTI), was linked to significant adverse effects on the CNS which may induce psychiatric symptoms, such as severe depression and suicidal ideation [25]. PLHIV receiving efavirenz were approximately twice as likely to experience suicidal thoughts or attempt suicide compared to those receiving other medications [26]. On the other hand, non-HIV-related risk factors did not vary between countries, which included female gender, young adult (18-34 years old), low educational level (secondary education or lower), married, and having a mental disorder [7]. While diagnosable mental disorders prior to suicidal behavior are more prevalent in HICs (>90\% versus $60 \%$ ), psychopathologies are as predictive of suicidal ideation in LMICs as they are in HICs [2, 27, 28]. Ultimately, psychopathology in PLHIV was found to affect the clinical outcome and mortality, adherence to ART, HIV risk behaviors, and quality of life (QOL) poorly $[11,17,29,30]$. Psychological interventions (e.g. cognitive behavioral therapy and group psychotherapy) in HICs are effective in improving depressive symptoms among PLHIV, as evidently shown by clinical trials [31-33]. Such studies also highlighted the importance of early detection of suicidal behavior in order to enable timely intervention to improve mental health and HIV/ AIDS-related treatment outcomes [34]. Nevertheless, more data are urgently needed in LMICs, including Indonesia.

Indonesia is the third most populous LMICs in the world and known to have the second largest burden of PLHIV in Asia [35, 36]. Although the suicide rate among general population in Indonesia (3.4 per 100,000 people) is lower than the crude suicide rate in both South-East Asia and worldwide (13.2 and 10.6 per 100,000 people, respectively), suicide is regarded as a major concern in Indonesia [1]. Suicidal ideation was reported in $4.75 \%$ of Indonesian adolescents [37], while a 2019 survey of 1018 adults in the general population reported that 1 of 4 subjects experienced suicidal thoughts [38]. With regard to PLHIV in Indonesia, however, the characteristic of suicidal ideation is practically unknown. In this study, we aim to identify suicidal ideation and psychopathology among PLHIV in Indonesia and the associated factors. Prior evidences in other countries signified depression as a major factor to the emergence of suicidal ideation among PLHIV [20, 39-41]. Thus, we hypothesize that Indonesian PLHIV who have experienced suicidal ideation will show significantly higher depression symptoms 
score. It is hoped that the result of this study is beneficial to optimize early psychological intervention, prevent suicide, and improve the overall HIV/AIDS treatment outcome in Indonesia.

\section{Methods}

\section{Demographics and data collection}

A cross-sectional study was conducted among subjects who met inclusion criteria, which were adult PLHIV aged 18-65 years old receiving antiretroviral therapy (ART) and fluent in Indonesian language. Subjects were excluded if severe mental disorders, including psychotic disorders as well as intellectual and developmental disabilities, were revealed during psychiatric examination. Power analysis with medium effect size $(d=0.50)$ and an alpha of 0.05 showed that a minimum size of 86 subjects was necessary to achieve a power of 0.90 . Subject recruitment was done by consecutive sampling and performed from July to October 2017 in HIV Integrated Service Unit of dr. Cipto Mangunkusumo General Hospital, Jakartathe largest outpatient clinic for HIV management and research center in Indonesia, which also serves as the national referral center for HIV/AIDS cases all over the country.

Subjects were requested to fill out measurement questionnaire and sociodemographic survey. Whenever the subjects could not independently fill in the questionnaires, interviews were done instead by three interviewers under the supervision of a licensed psychiatrist. Assessment of suicidal ideation was done via direct interview, while HIV-related data (symptoms of fever, fatigue, pharyngitis, lymphadenopathy, myalgia, and chronic diarrhea with the results of a positive enzymelinked immunosorbent assay [ELISA] examination) were procured from medical records. Written informed consents were obtained from all recruited subjects, confidentiality of the subjects' responses was ensured, and permission to retrieve data from subjects' medical record was also obtained.

\section{Measurements}

Sociodemographic data on gender, age, residence, education, monthly income (with brackets based on Riset Kesehatan Dasar or Indonesian National Health Survey in 2013), religion, ethnic group, marital status, and presence of cohabitant were collected. HIV-related data including duration of HIV diagnosis, latest CD4 count, ART regiment, ART duration, and presence of opportunistic infection were also obtained. CD4 count is the number of CD4-expressing $\mathrm{T}$ cells per microliter of blood, with normal range of $500-1400$ cells $/ \mu \mathrm{L}-\mathrm{CD} 4$ cells has important roles in adaptive immune systems and are the main cells destroyed by HIV. ART regiments were defined as the last antiretroviral drugs taken to suppress HIV replication inside the body.
Finally, lifetime suicidal ideation was recorded if the subjects responded with "yes" to the following question, "Have you ever seriously thought about committing suicide?" Similar method of assessment was done in other studies $[8,20,42]$. The question was taken from a section of World Mental Health-Composite International Diagnostic Interview (WMH-CIDI) suicidality assessment [43].

\section{Symptoms check list 90 (SCL-90) questionnaire}

The subscales of depression and anxiety of the Symptoms Check List 90 (SCL-90) questionnaire, translated into Indonesian, were used. SCL-90 is a self-report psychometric instrument that is used to quantitatively assess mental status, consisting of 90 items, each with five-point Likert scale: 'not at all', 'a little bit', 'moderately', 'quite a bit', and 'extremely'. The instrument is divided into nine psychiatric symptom and psychological distress subscales. SCL90 was translated into Indonesian and validated by Herianto et al. with good validity and reliability. Reliability test revealed a Cronbach's alpha of 0.67 with the highest of 0.94 on the depression subscale. The Indonesian version of SCL-90 was conducted using cut-off T-score of $>60$ to screen psychopathologies, yielding sensitivity of $82.92 \%$, specificity of $83 \%$, positive predictive value of $80.0 \%$, and negative predictive value of $84.7 \%$ [44].

\section{Statistical analyses}

Statistical analyses were conducted using STATA 14 (StataCorp, TX, USA). Chi-square or t-tests were done for bivariate analyses, and 2-tailed $p$ value of less than 0.05 was considered significant. Age as well as depressive and anxiety symptoms as measured by SCL-90 were regarded as continuous variables, while the rest of covariates were nominal variables. Due to the low number of recruited subjects, multivariate analysis was conducted using Firth's penalized logistic regression (firthlogit command in STATA) which shrinks the regression coefficient towards zero, for variables with $p<0.25$ in the bivariate analyses.

\section{Results}

\section{Baseline demographics}

A total of 86 subjects met the inclusion criteria. All approached subjects agreed to participate in the study and completed the questionnaire without any missing data. Most recruited subjects were male (65.1\%) with median age of 35 years (Table 1). Most subjects came from relatively low socioeconomic strata, in which the majority were high school graduates $(44.2 \%)$ and had monthly income less than IDR 1,500,000 (53.5\%, equivalent to USD 107). More than half of subjects were not married (53.5\%) and living together with their family $(67.4 \%)$. 
Table 1 Demographic characteristics of study subjects $(N=86)$

\begin{tabular}{|c|c|}
\hline Variables & Frequency (\%) \\
\hline \multicolumn{2}{|l|}{ General demographics } \\
\hline \multicolumn{2}{|l|}{ Gender } \\
\hline Male & $56(65.1)$ \\
\hline Female & $30(34.9)$ \\
\hline \multicolumn{2}{|l|}{ Age (years) } \\
\hline Median, IQR & $35.0,31.3-38.0$ \\
\hline $18-34$ & $40(46.5)$ \\
\hline $35-65$ & $46(53.5)$ \\
\hline \multicolumn{2}{|l|}{ Residence } \\
\hline Jakarta & $56(65.1)$ \\
\hline Outside Jakarta & $30(34.9)$ \\
\hline \multicolumn{2}{|l|}{ Education } \\
\hline Middle school or lower & $11(12.8)$ \\
\hline High school & $38(44.2)$ \\
\hline Higher education & $37(43.0)$ \\
\hline \multicolumn{2}{|l|}{ Monthly income (IDR) } \\
\hline$<1,500,000(<107$ USD $)$ & $46(53.5)$ \\
\hline$\geq 1,500,000$ ( $\geq 107$ USD) & $40(46.5)$ \\
\hline \multicolumn{2}{|l|}{ Religion } \\
\hline Islam & $60(69.8)$ \\
\hline Protestant & $20(23.3)$ \\
\hline Catholic & $3(3.5)$ \\
\hline Hinduism & $1(1.2)$ \\
\hline Buddhism & $2(2.3)$ \\
\hline \multicolumn{2}{|l|}{ Ethnic group } \\
\hline Javanese & $35(40.7)$ \\
\hline Sundanese & $14(16.3)$ \\
\hline Betawi & $5(5.8)$ \\
\hline Batak & $6(7.0)$ \\
\hline Chinese-Indonesian & $11(12.8)$ \\
\hline Others & $15(17.4)$ \\
\hline \multicolumn{2}{|l|}{ Marital status } \\
\hline Married & $40(46.5)$ \\
\hline Single & $32(37.2)$ \\
\hline Divorced & $14(16.3)$ \\
\hline \multicolumn{2}{|l|}{ Living together with } \\
\hline Alone & $12(14.0)$ \\
\hline Partner & $16(18.6)$ \\
\hline Family & $58(67.4)$ \\
\hline \multicolumn{2}{|l|}{ HIV-related } \\
\hline \multicolumn{2}{|c|}{ Duration of HIV diagnosis (years) } \\
\hline Median, IQR & $5,2-9$ \\
\hline$<2$ & $25(29.1)$ \\
\hline$\geq 2$ & $61(70.9)$ \\
\hline
\end{tabular}

Table 1 Demographic characteristics of study subjects $(N=86)$ (Continued)

\begin{tabular}{ll}
\hline Variables & Frequency (\%) \\
\hline Latest CD4 count (cells/ $\boldsymbol{\mu l}$ ) & \\
$\quad$ Median, IQR & $463,258-654$ \\
$\quad<500$ & $35(40.7)$ \\
$\geq 500$ & $51(59.3)$ \\
ART regiment & \\
$\quad$ Efavirenz-based & $42(48.8)$ \\
Other NNRTI-based & $32(37.2)$ \\
PI-based & $12(14.0)$ \\
ART duration (years) & \\
Median, IQR & $4,1-8$ \\
$<2$ & $31(36.1)$ \\
$\geq 2$ & $55(63.9)$ \\
Opportunistic infections & \\
Present & $31(36.0)$ \\
Absent & $55(64.0)$
\end{tabular}

IQR interquartile range, IDR Indonesian Rupiah, USD United States Dollar, CD4 cluster of differentiation 4, ART antiretroviral therapy, NNRTI non-nucleoside reverse transcriptase inhibitor, $P I$ protease inhibitor

Subjects were mostly PLHIV who had long-term treatment in the hospital, with median duration since HIV diagnosis of 5 years. Most subjects (51.2\%) were using efavirenz-based regiment and median duration of ART use among all subjects was 4 years. HIV infection was generally well-controlled under therapy as most subjects (59.3\%) had CD4 count of more than 500 cells/ $\mu \mathrm{l}$.

Suicidal ideation, psychopathology and associated factors Using a cut-off T-score of 61, the SCL-90 measurements identified $15(17.4 \%)$ and 13 (15.1\%) subjects with depression and anxiety symptoms, respectively. Presence of both depression and anxiety symptoms were identified in 10 (11.6\%) subjects, while 68 (79.1\%) subjects had neither.

Out of 86 subjects, lifetime suicidal ideation was identified in 20 (23.3\%) (Table 2). Mean T-score for both depressive and anxiety symptoms were significantly higher among subjects with suicidal ideation $(M=60.75, S D=12.0, p=0.000$ and $M=57.9, S D=2.8$, $p=0.001$, respectively). Non-marital status was also an associated factor, since 12 out of 32 subjects who were single had suicidal ideation $\left[\chi^{2}(1, N=86)=7.36, p=\right.$ $0.009]$. No association was found with the remaining demographical data, including age, gender, education, monthly income, and presence of cohabitant. Among HIV-related covariates, the latest CD4 count of less than 500 cells/ $\mu$ l was significantly associated with lifetime suicidal ideation $\left[\chi^{2}(1, N=86)=8.67, p=0.003\right]$. Efavirenz use was also associated with suicidal ideation $\left[\chi^{2}(1, N=86)=4.67, \quad p=.031\right]$. Duration since HIV 
Table 2 Bivariate analyses between psychopathology and other determining factors with suicidal ideation

\begin{tabular}{|c|c|c|c|c|}
\hline & With suicidal ideation $(N, \%)$ & Without suicidal ideation (N, \%) & $p$ & COR $(95 \% \mathrm{Cl})$ \\
\hline \multicolumn{5}{|l|}{ Psychopathology (T-score) } \\
\hline Depression (mean, SD) & $60.8(12.0)$ & $46.7(6.6)$ & 0.000 & $1.16(1.09-1.24)$ \\
\hline Anxiety (mean, SD) & $57.9(2.8)$ & $47.7(1.0)$ & 0.001 & $1.10(1.04-1.17)$ \\
\hline Age (median, IQR) & $35.5(32.5-38.5)$ & $34(30.0-37.0)$ & 0.277 & $0.96(0.89-1.03)$ \\
\hline \multicolumn{5}{|l|}{ Gender } \\
\hline Female & $6(30.0)$ & $24(36.4)$ & 0.798 & $0.75(0.26-2.21)$ \\
\hline Male & $14(70.0)$ & $42(63.6)$ & & \\
\hline \multicolumn{5}{|l|}{ Education } \\
\hline Middle school or lower & $4(20.0)$ & $7(10.6)$ & 0.272 & $0.48(0.12-1.83)$ \\
\hline High school or higher & $16(80.0)$ & $59(89.4)$ & & \\
\hline \multicolumn{5}{|l|}{ Monthly income } \\
\hline Low & $14(70.0)$ & $32(48.5)$ & 0.152 & $2.48(0.85-7.24)$ \\
\hline Middle and high & $6(30.0)$ & $34(51.5)$ & & \\
\hline \multicolumn{5}{|l|}{ Marital status } \\
\hline Single & $12(60.0)$ & $20(30.3)$ & 0.009 & $5.40(1.53-18.97)$ \\
\hline Divorced & $4(20.0)$ & $10(15.2)$ & 0.106 & $3.60(0.76-17.01)$ \\
\hline Married $^{a}$ & $4(20.0)$ & $36(54.5)$ & & \\
\hline \multicolumn{5}{|l|}{ Living with } \\
\hline Nobody & $4(20.0)$ & $8(12.1)$ & 0.289 & \\
\hline Family & $16(80.0)$ & $58(87.9)$ & & $1.81(0.48-6.80)$ \\
\hline \multicolumn{5}{|l|}{ Latest CD4 count (cells/ul) } \\
\hline$<500$ & $16(80.0)$ & $28(42.4)$ & 0.003 & \\
\hline$\geq 500$ & $4(20.0)$ & $38(57.6)$ & & $5.43(1.63-18.01)$ \\
\hline \multicolumn{5}{|l|}{ Opportunistic infections } \\
\hline Present & $9(45.0)$ & $22(33.3)$ & 0.493 & \\
\hline Absent & $11(55.0)$ & $44(66.7)$ & & $1.64(0.59-4.53)$ \\
\hline \multicolumn{5}{|l|}{ ART regiment } \\
\hline Efavirenz-based & $14(70.0)$ & $28(42.4)$ & 0.031 & \\
\hline Not efavirenz-based & $6(30.0)$ & $38(57.6)$ & & $3.17(1.08-9.27)$ \\
\hline \multicolumn{5}{|l|}{ Duration of HIV diagnosis } \\
\hline$<2$ years & $4(20.0)$ & $21(31.8)$ & 0.460 & \\
\hline$\geq 2$ years & $16(80.0)$ & $45(68.2)$ & & $0.54(0.16-1.80)$ \\
\hline \multicolumn{5}{|l|}{ ART duration } \\
\hline$<2$ years & $5(25.0)$ & $26(39.4)$ & 0.364 & \\
\hline$\geq 2$ years & $15(75.0)$ & $40(60.6)$ & & $0.51(0.17-1.58)$ \\
\hline Total & $20(23.3)$ & $66(76.7)$ & & \\
\hline
\end{tabular}

areference group

diagnosis, duration of ART use, and presence of opportunistic infections were non-associative.

Based on the results of bivariate analyses as well as prior evidences, the following covariates were included into penalized logistic regression model: age, gender, marital status, depression symptoms, anxiety symptoms, latest CD4 count, and efavirenz use (Table 3). Among all variables, depressive symptoms $(p=0.004, \mathrm{AOR} 1.26$,
95\% CI 1.08-1.48) and efavirenz use ( $p=0.048$, AOR 5.00 , 95\% CI 1.02-24.6) were identified as the significant factors related to the presence of lifetime suicidal ideation.

\section{Discussion}

We have identified the prevalence of lifetime suicidal ideation among Indonesian PLHIV to be 23.3\%. This 
Table 3 Multivariate analysis between selected determining factors with suicidal ideation

\begin{tabular}{lll}
\hline Covariate & $p$ & AOR (95\% Cl) \\
\hline Older age & 0.052 & $0.89(0.79-1.01)$ \\
Female gender & 0.183 & $3.52(0.55-22.47)$ \\
Non-marital status & 0.069 & $4.28(0.90-20.48)$ \\
1-point increase in SCL-90 depressive symptoms T-score & $\mathbf{0 . 0 0 4}$ & $\mathbf{1 . 2 6}(\mathbf{1 . 0 8 - 1 . 4 8 )}$ \\
1-point increase in SCL-90 anxiety symptoms T-score & 0.192 & $0.91(0.79-1.05)$ \\
Latest CD4 $<500$ cells/ $\mu$ l & 0.057 & $3.35(0.77-14.6)$ \\
Efavirenz use & $\mathbf{0 . 0 4 8}$ & $\mathbf{5 . 0 0 ( 1 . 0 2 - 2 4 . 6 )}$ \\
\hline
\end{tabular}

number is comparable to prior studies among PLHIV in both HICs and LMICs: $31 \%$ had current suicidal ideation among PLHIV in UK [45], 14\% (suicidal ideation at any time point or lifetime) and $19 \%$ (at present time) in the United States [39, 46], 21\% (in the past) in Australia [47], 14\% (lifetime) in India [48], 22.5 to $33.6 \%$ (lifetime) in Ethiopia [20, 41], 8.8\% (lifetime) in Uganda [49], and $28.8 \%$ (current) in South Africa [50].

We also analyzed independent covariates from demographic factors, psychopathology, and HIV-related variables; five were found associative to suicidal ideationdepressive symptoms, anxiety symptoms, single marital status, latest CD4 count of less than 500 cells $/ \mu$ l, and efavirenz use. Depression and anxiety symptoms are frequently discovered among PLHIV, and both manifestations have been linked strongly to the development of suicidal ideation $[51,52]$. Depression among PLHIV can be precipitated by chronic HIV-related conditions, adverse effects of medication (e.g. efavirenz), as well as social pressures (e.g. difficulty of finding partner, jobs, and negative stigma from the community) [17, 53, 54]. Similar facets have been shown to trigger anxiety among PLHIV in LMICs [55-57]. Ultimately, depression and anxiety may lead to higher risk of suicidal ideation in PLHIV compared to those in HIV seronegative population [10, 40]. Prevalence of depression found in our study, however, was relatively low (17.4\%), which may be caused by the psychometric weakness of SCL-90 or the small sample size. Nevertheless, depression prevalence rates among PLHIV were generally reported in many studies to be highly diverse $(0-80 \%)$ due to differences in target subpopulation or instrument cut-off points [58, 59]. In this study, cut-off T-score of SCL-90 was set to be $>60$, but eventually we included $\mathrm{T}$-score in the regression model as a continuous variable. Subsequent multivariate analysis confirmed 1-point increase in depressive symptoms subscale as an independent factor, with AOR of 1.26, toward the presence of suicidal ideation.

We did not find association between age and suicidal ideation in PLHIV. This differs with findings in general population where the association between depression and suicidal behavior are stronger in the elderly population [60]. Furthermore, study among PLHIV by Schlebusch et al. in South Africa reported that HIV seropositive status, age, and gender were all associated with suicidal ideation [21]. The discrepancy is most likely due to the small sample size in our study. Gender also did not correlate with suicidal ideation in our study, in contrast to the report by Bitew et al. in Ethiopia in which female PLHIV were found to be 2.3 times more likely to have suicidal ideation compared to male PLHIV [41]. Gebremariam et al. discovered that female PLHIV in Ethiopia were more likely to have suicidal ideation due to daily burden as housewives and perceived negativity of depending on men [20]. Study in Brazil by Ceccon et al. also reported that $50 \%$ of female PLHIV had risk of suicidal ideation, which may relate to gender violence [61]. Non-associative result in our study was most likely due to limited sample size and subject variability. Survey by Ministry of Health of Indonesia in 2018 showed that the distribution of PLHIV in Indonesia was leaning towards male in a 2:1 ratio [62], and consecutive sampling method would naturally led to more male subjects. A targeted study towards female participants may further elucidate the association of gender with suicidal behavior; a study that is warranted in LMICs.

Several existing studies reported the correlation between low income and suicidal ideation in PLHIV. Onyebueke and Okwaraji described correlation between low income among PLHIV in Nigeria with depression and increased risk of suicidal ideation [63]. Financial constraints and difficulty in getting better jobs increases stigma, psychosocial stress, and risk of psychopathology $[21,63]$. The only related data collected in this study was monthly income; further exploration into occupational status and economic QOL may further explain the role of socioeconomic status in suicidal behavior among PLHIV. Indeed, correlation of income with QOL has been robustly shown in both HICs and LMICs, affecting both mental health and peer perception, as well as stigma from the local community [64, 65].

Socio-environmental condition is heavily linked to mental health problems, including in PLHIV. Perception 
of solitude among PLHIV is significantly associated to depression and suicidal ideation as studied in several countries. For example, unmarried subjects had higher rate of depressive behavior in India [53], and solitary living condition among PLHIV in Ethiopia increased the likelihood of suicidal ideation by 13.5 times [41]. In our study, unmarried subjects had significantly higher rate of suicidal ideation in bivariate analyses while the presence of cohabitants was non-associative. Non-marital status and presence of cohabitants, however, may not correlate with the actual presence of social support. Exclusion and the feeling of being isolated from surroundings might directly relate to depression and suicidal thoughts-37\% of PLHIV experienced loneliness and social isolation due to their HIV seropositive status, which correlated with depressive symptoms [66].

In our study, CD4 cell count of $<500$ cells $/ \mu \mathrm{L}$ was not independently associated with lifetime suicidal ideation. This is contrary with result by Bitew et al., who reported CD4 count $<500$ cells $/ \mu \mathrm{L}$ as a predictive factor of suicidal thoughts with AOR of 2.5 [41]. Amanor-Boadu et al. went further and defined CD4 count as a clinical marker of untreated depression in African-American PLHIV [67]. In progressive HIV disease, low CD4 count was associated with AIDS defining illness and increasing mortality, while untreated depression and poor ART adherence were independently associated with poorer CD4 outcomes [63]. Discrepancy in result might be due to the smaller sample size in our study compared to the aforementioned studies. Also in contrast to our study, Bitew et al. stated strong correlation between opportunistic infections, depression, and suicidal ideation [41]. Risk of suicide may increase due to severe physical conditions such as muscle wasting, or direct pathogenesis to the CNS via opportunistic infections or HIV-associated neurocognitive disorder (HAND), or vice versa-depression is also predictive of frailty phenotype and HAND [41, 68-70]. Opportunistic infections tend to be more severe as CD4 count decrease below 200 cells $/ \mu \mathrm{L}$; however, infections do not always occur in low CD4 state. Decline in immune status itself may negatively affect mental state and induce psychological frailty, rather than actual opportunistic infections to the CNS or other organ systems [12, 70]. In our study, most subjects already received ART for years which presumably led to relatively high median CD4 count and low occurrence of opportunistic infections. Recruitment of newly-diagnosed or untreated patients may further shed light on the correlation between suicidal behavior, immune dysfunction, and AIDS.

Regression model confirmed that the use of efavirenzbased ART regiment is associated to suicidal ideation in this study, with AOR of 5.00. Use of efavirenz has long been associated with CNS-related adverse effects including but not limited to dizziness, fatigue, nightmares, and insomnia [71, 72]. Specifically, long-term efavirenz use is associated with neuropsychiatric disorders, including depression and suicidal ideation lasting for several months [72, 73]. In 2015, Mothapo et al. reported that efavirenz discontinuation improved depressive symptoms as measured by SCL90 [74]. Studies in animal models showed that efavirenz evidently disrupted brain mitochondrial P450 systems and neurochemical balance, particularly serotonin, both of which led to its neurotoxic effects [75, 76]. Yet, the link to depressive behavior remains controversial. Study by Mollan et al. concluded that efavirenz was associated with 2-fold increased risk of suicidality [26], while a newer study by Dabaghzadeh et al. in 2015 did not found any correlation [77] and Chang et al. in 2018 reported that suicidal thoughts did not occur more frequently in efavirenz recipients compared to another commonly used NNRTI, nevirapine [78]. The author opined that efavirenz is metabolically processed slower, resulting in lower peak levels and less CNS toxicity [78] while long duration of use is also known to induce tolerance towards CNS-related adverse effects [79]. Nevertheless, the specific association between efavirenz and suicidal ideation seems to be understudied. A lot of other studies with similar method to our study did not analyze the types of ART regiments used [20, 41]. Further studies are warranted.

The duration of both HIV diagnosis and ART use did not associate with suicidal ideation in this study. These data are supported by Dabaghzadeh et al. who evidently showed no correlation between duration of HIV diagnosis (median 24 months) and ART use (median 27 months) with suicidal ideation among PLHIV in Iran [77]. However, Olley et al. stated that patients who were diagnosed early with HIV might experience reduced stress over time after a period of adaptation [80]. Furthermore, study by Amiya et al. in Nepal added that stress associated with suicidal ideation arises early after HIV diagnosis due to inadaptation and absence of effective coping mechanism towards HIV seropositive status, which palliates over time [81]. Govender and Schlebusch also reported significant association between depression and feelings of hopelessness with HIV diagnosis of less than 6 weeks in South Africa [50]. Similar to low immune status, recruitment of newly-diagnosed PLHIV may better characterize the link between suicidal behavior to shorter duration of diagnosis and ART use.

\section{Strengths and limitations}

This study is the first to identify suicidal ideation, associated psychopathology, and determining factors among PLHIV in Indonesia. We also included HIV-related covariates into the analyses, including the use of efavirenz as ART regiment, which was subsequently found to be a significant associated factor. This study also highlights 
the association between depressive symptoms and suicidal ideation among PLHIV, and thus, depression screening in HIV integrated care should be regarded as a mandatory service. However, since SCL-90 was a screening instrument, clinical diagnosis of psychiatric problems has to be reaffirmed by interview using diagnostic criteria. Reliance on SCL-90 as a diagnostic tool may introduce bias in the outcome of our study and inclusion of accurate psychiatric diagnosis in future studies may provide stronger link between HIV and psychopathologies.

A number of other limitations can be identified. The cross-sectional nature limits any establishment of causality between independent and dependent variables. Thorough observation on opportunistic infections and HIV clinical stages may better illustrate the link between physical and psychological comorbidities in PLHIV. Other potentially important socio-environmental variables were not assessed, e.g. social support, acceptance of HIV status, perceived stigma on HIV status, occupational status, and access to health care services. Lifetime instead of point prevalence was assessed, which only predicted the presence of suicidal ideation rather than its emergence. In addition, the ascertainment of suicidal ideation was done with a single question instead of a validated scale. Further study about characterization of suicidal attempt should be performed, which may enable an analysis of progression from ideation to realization. We also hope that further studies in LMIC could examine the implications specifically for women with HIV (e.g. [61]), and PLHIV with shorter duration of diagnosis and therapy. Most importantly, the small sample size of this study and lack of control group means that representation of results is not optimally accurate and therefore needs to be interpreted carefully. Longitudinal study with much larger sample size is warranted in Indonesia, as well as LMICs in general.

\section{Conclusion}

We have identified the prevalence of suicidal ideation among Indonesian PLHIV on ART to be $23.3 \%$. Suicidal ideation is significantly associated with the psychopathology of depressive symptoms, anxiety symptoms, single marital status, CD4 count $<500$ cells $/ \mu$ l, and efavirenz use. Depressive symptoms and efavirenz use are independent factors associated with the presence of lifetime suicidal ideation. Based on these results, we recommend that early screening of psychopathology and suicidal ideation in PLHIV, as well as substituting efavirenz with other ART medications are imperative to promote early psychological intervention, prevent suicide, and improve the overall HIV/AIDS treatment outcome in Indonesia.

\section{Abbreviations}

HIV: Human immunodeficiency virus; AIDS: Acquired immune deficiency syndrome; ART: Antiretroviral therapy; SCL-90: Symptom checklist-90;
PLHIV: People living with HIV; CD4: Cluster of differentiation 4; LMICs: Lowand middle-income countries; HICs: High-income countries

\section{Acknowledgements}

We would like to thank Darma Imran for the kind authorization to conduct data collection in the HIV Integrated Service Unit of Cipto Mangunkusumo Hospital. We also thank Chika Yamada for her substantial help in statistical analyses and manuscript writing. Finally, we are exceptionally grateful to the study subjects.

\section{Authors' contributions}

$\mathrm{YO}, \mathrm{A}$, and $\mathrm{KS}$ planned the study. A, MW, GA, EH, RD, and KS conducted data collection. $Y O, A, M W, G A, E H, R D$, and $K S$ analyzed and interpret the data. $\mathrm{YO}, \mathrm{KS}$, and $\mathrm{YH}$ wrote the manuscript. All authors have read and approved the final manuscript.

\section{Funding}

This study was partly supported by Grant-in-Aid for Scientific Research (KAKENHI) from the Japan Society for the Promotion of Science (grant number 19 K17925 to YO).

\section{Availability of data and materials}

Datasets used in this study are available from the corresponding author (KS) upon request

\section{Ethics approval and consent to participate}

This study was approved by the Ethics Committee of Faculty of Medicine, Universitas Indonesia (letter no. 659/UN2.F1.D1/KBK/PDP.01/2017). Written informed consents were obtained from all recruited subjects and confidentiality of the subjects' responses was ensured. Permission to retrieve data from subjects' medical record was also obtained.

\section{Consent for publication}

Not applicable.

\section{Competing interests}

The authors declare no competing interest.

\section{Author details}

${ }^{1}$ Department of Pathology, Graduate School of Medicine, Kobe University, Kobe, Japan. ${ }^{2}$ Department of Psychiatry, Faculty of Medicine, Universitas Indonesia, 71 Diponegoro, Central Jakarta, DKI, Jakarta, Indonesia.

Received: 24 October 2019 Accepted: 13 May 2020

Published online: 24 May 2020

\section{References}

1. World Health Organization. Mental health: Suicide data. 2018. https://www. who.int/mental_health/prevention/suicide/suicideprevent/en/. Accessed 20 Oct 2019.

2. Vijayakumar L, Nagaraj K, Pirkis J, Whiteford H. Suicide in developing countries (1): frequency, distribution, and association with socioeconomic indicators. Crisis. 2005;26:104-11.

3. Klonsky ED, May AM, Saffer BY. Suicide, suicide attempts, and suicidal ideation. Annu Rev Clin Psychol. 2016;12:307-30.

4. Sadock BJ, Sadock VA, Ruiz P. Mood disorder. In: Sadock BJ, Sadock VA, Ruiz P, editors. Kaplan \& Sadock's synopsis of psychiatry: behavioral sciences/ clinical psychiatry. 11th ed. Philadelphia: Wolters Kluwer; 2014. p. 78-9.

5. Crosby A, Ortega L, Melanson C. Self-directed violence surveillance: Uniform definitions and recommended data elements (version 1.0). 2011. p. 11-7. https://www.cdc.gov/violenceprevention/pdf/Self-Directed-Violence-a.pdf. Accessed 20 Oct 2019.

6. Centers for Disease Control and Prevention. Definitions: Self-directed violence. Atlanta; 2015. http://www.cdc.gov/violenceprevention/suicide/ definitions.html. Accessed 20 Oct 2019.

7. Nock MK, Borges G, Bromet EJ, Alonso J, Angermeyer M, Beautrais A, et al. Cross-national prevalence and risk factors for suicidal ideation, plans and attempts. Br J Psychiatry. 2008;192:98-105.

8. Borges G, Nock MK, Abad JMH, Hwang I, Sampson NA, Alonso J, et al. Twelve-month prevalence of and risk factors for suicide attempts in the 
world health organization world mental health surveys. J Clin Psychiatry. 2010;71:1617-28.

9. Jia C-X, Mehlum L, Qin P. AIDS/HIV infection, comorbid psychiatric illness, and risk for subsequent suicide: a nationwide register linkage study. J Clin Psychiatry. 2012;73:1315-21.

10. Schadé A, van Grootheest G, Smit JH. HIV-infected mental health patients: characteristics and comparison with HIV-infected patients from the general population and non-infected mental health patients. BMC Psychiatry. 2013;13:35.

11. Whetten $K$, Reif S, Whetten R, Murphy-Mcmillan LK. Trauma, mental health, distrust, and stigma among HIV-positive persons: implications for effective care. Psychosom Med. 2008;70:531-8.

12. Williams $\mathrm{E}$, Catalan J. The changing profile of mental health problems in people with HIV. Psychiatry. 2009;8:216-22.

13. Lampe F, Miners A, Kreif N. Comparison of depression and anxiety between HIV-positive and HIV-negative people. In: 22nd International AIDS Conference. Amsterdam: International AIDS Society; 2018. http:// programme.aids2018.org/Abstract/Abstract/9417. Accessed 20 Oct 2019.

14. Mascolini M. Higher depression and anxiety rates with HIV across ART and viral load categories. In: 22nd International AIDS Conference. Amsterdam: International AIDS Society; 2018. http://www.natap.org/2018/IAC/IAC_57. htm. Accessed 20 Oct 2019.

15. Wang T, Fu H, Kaminga AC, Li Z, Guo G, Chen L, et al. Prevalence of depression or depressive symptoms among people living with HIV/AIDS in China: a systematic review and meta-analysis. BMC Psychiatry. 2018;18:160.

16. Chandra P, Jayarajan N. HIV and mental health: an overview of research from India. Indian J Psychiatry. 2010;52:269.

17. Deshmukh NN, Borkar AM, Deshmukh JS. Depression and its associated factors among people living with HIV/AIDS: can it affect their quality of life? J Fam Med Prim Care. 2017;6:549-53.

18. Collins PY, Holman AR, Freeman MC, Patel V. What is the relevance of mental health to HIV/AIDS care and treatment programs in developing countries? A systematic review. AIDS. 2006;20:1571-82.

19. Mayston R, Kinyanda E, Chishinga N, Prince M, Patel V. Mental disorder and the outcome of HIV/AIDS in low-income and middle-income countries: a systematic review. AIDS. 2012;26(SUPPL.2):S117-35.

20. Gebremariam EH, Reta MM, Nasir Z, Amdie FZ. Prevalence and associated factors of suicidal ideation and attempt among people living with HIV/AIDS at Zewditu memorial hospital, Addis Ababa, Ethiopia: A cross-sectional study. Psychiatry J. 2017;2017:1-8.

21. Schlebusch L, Vawda N. HIV-infection as a self-reported risk factor for attempted suicide in South Africa. African J Psychiatry (South Africa). 2010;13:280-3.

22. Sivasubramanian M, Mimiaga MJ, Mayer KH, Anand VR, Johnson CV, Prabhugate $\mathrm{P}$, et al. Suicidality, clinical depression, and anxiety disorders are highly prevalent in men who have sex with men in Mumbai, India: findings from a community-recruited sample. Psychol Heal Med. 2011; 16:450-62.

23. Catalan J, Harding R, Sibley E, Clucas C, Croome N, Sherr L. HIV infection and mental health: suicidal behaviour - systematic review. Psychol Heal Med. 2011;16:588-611.

24. Keiser O, Spoerri A, Brinkhof MWG, Hasse B, Gayet-Ageron A, Tissot F, et al. Suicide in HIV-infected individuals and the general population in Switzerland, 1988-2008. Am J Psychiatry. 2010;167:143-50.

25. O'Mahony SM, Myint AM, Steinbusch H, Leonard BE. Efavirenz induces depressive-like behaviour, increased stress response and changes in the immune response in rats. Neuroimmunomodulation. 2005;12:293-8.

26. Mollan KR, Smurzynski M, Eron JJ, Daar ES, Campbell TB, Sax PE, et al. Association between efavirenz as initial therapy for HIV-1 infection and increased risk for suicidal ideation or attempted or completed suicide: an analysis of trial data. Ann Intern Med. 2014;161:1-10.

27. Cavanagh JTO, Carson AJ, Sharpe M, Lawrie SM. Psychological autopsy studies of suicide: a systematic review. Psychol Med. 2003;33:395-405.

28. Vijayakumar L. Suicide prevention: the urgent need in developing countries. World Psychiatry. 2004;3:158-9.

29. Ickovics JR, Hamburger ME, Vlahov D, Schoenbaum EE, Schuman P, Boland RJ, et al. Mortality, CD4 cell count decline, and depressive symptoms among HIV-seropositive women: longitudinal analysis from the HIV epidemiology research study. JAMA. 2001;285:1466-74.

30. Mills EJ, Nachega JB, Bangsberg DR, Singh S, Rachlis B, Wu P, et al. Adherence to HAART: a systematic review of developed and developing nation patient-reported barriers and facilitators. PLoS Med. 2006;3:e438.
31. Himelhoch S, Medoff DR, Oyeniyi G. Efficacy of group psychotherapy to reduce depressive symptoms among HIV-infected individuals: a systematic review and meta-analysis. AIDS Patient Care STDs. 2007;21:732-9.

32. Safren SA, O'Cleirigh C, Tan JY, Raminani SR, Reilly LC, Otto MW, et al. A randomized controlled trial of cognitive behavioral therapy for adherence and depression (CBT-AD) in HIV-infected individuals. Health Psychol. 2009;28:1-10.

33. Crepaz N, Passin WF, Herbst JH, Rama SM, Malow RM, Purcell DW, et al. Meta-analysis of cognitive-behavioral interventions on HIV-positive persons' mental health and immune functioning. Health Psychol. 2008:27:4-14.

34. Angelino AF, Treisman GJ. Management of psychiatric disorders in patients infected with human immunodeficiency virus. Clin Infect Dis. 2001;33:847-56.

35. The World Bank. New Country Classifications | Data: The World Bank Group. 2020. https://datahelpdesk.worldbank.org/knowledgebase/articles/906519world-bank-country-and-lending-groups. Accessed 26 Feb 2020.

36. UNAIDS. Indonesia. UNAIDS. 2016. https://www.unaids.org/en/ regionscountries/countries/indonesia. Accessed 20 Oct 2019.

37. Putra IGNE, Karin PAES, Ariastuti NLP. Suicidal ideation and suicide attempt among Indonesian adolescent students. Int J Adolesc Med Health. 2019. https://doi.org/10.1515/ijamh-2019-0035.

38. Ho K. A quarter of Indonesians have experienced suicidal thoughts: YouGov. 2019. https://id.yougov.com/id/news/2019/06/26/quarter-indonesians-haveexperienced-suicidal-thou/. Accessed 20 Oct 2019.

39. Carrico AW, Johnson MO, Morin SF, Remien RH, Charlebois ED, Steward WT, et al. Correlates of suicidal ideation among HIV-positive persons. AIDS. 2007; 21:1199-203.

40. Le Wu Y, Yang HY, Wang J, Yao H, Zhao X, Chen J, et al. Prevalence of suicidal ideation and associated factors among HIV-positive MSM in Anhui, China. Int J STD AIDS. 2015;26:496-503.

41. Bitew H, Andargie G, Tadesse A, Belete A, Fekadu W, Mekonen T. Suicidal ideation, attempt, and determining factors among HIV/AIDS patients, Ethiopia. Depress Res Treat. 2016;2016:8913160.

42. Mu H, Li Y, Liu L, Na J, Yu L, Bi X, et al. Prevalence and risk factors for lifetime suicide ideation, plan and attempt in Chinese men who have sex with men. BMC Psychiatry. 2016;16:117.

43. Kessler RC, Ustün BB. The world mental health $(\mathrm{WMH})$ survey initiative version of the World Health Organization (WHO) composite international diagnostic interview (CIDI). Int J Methods Psychiatr Res. 2004;13:93-117.

44. Herianto M. Standardization and normalization of SCL-90 scores as a psychometric instrument. Thesis. Jakarta: Universitas Indonesia; 1994.

45. Sherr L, Lampe F, Fisher M, Arthur G, Anderson J, Zetler S, et al. Suicidal ideation in UK HIV clinic attenders. AIDS. 2008;22:1651-8.

46. Lawrence ST, Willig JH, Crane HM, Ye J, Aban I, Lober W, et al. Routine, selfadministered, touch-screen, computer-based suicidal ideation assessment linked to automated response team notification in an HIV primary care setting. Clin Infect Dis. 2010;50:1165-73.

47. Kelly B, Raphael B, Judd F, Perdices M, Kernutt G, Burnett P, et al. Suicidal ideation, suicide attempts, and HIV infection. Psychosomatics. 1998:39:405-15.

48. Chandra PS, Ravi V, Puttaram S, Desai A. HIV and mental illness. Br J Psychiatry. 1996;168:654.

49. Rukundo GZ, Mishara BL, Kinyanda E. Burden of suicidal ideation and attempt among persons living with HIV and AIDS in semiurban Uganda. AIDS Res Treat. 2016;2016:1-9.

50. Govender RD, Schlebusch L. Hopelessness, depression and suicidal ideation in HIV-positive persons. South African J Psychiatry. 2012;18:16-21.

51. Savard J, Laberge B, Gauthier JG, Ivers H, Bergeron MG. Evaluating anxiety and depression in HIV-infected patients. J Pers Assess. 1998;71:349-67.

52. Savard J, Laberge B, Gauthier JG, Bergeron MG. Screening clinical depression in HIV-seropositive patients using the hospital anxiety and depression scale. AIDS Behav. 1999;3:167-75. https://doi.org/10.1023/A: 1025444225120

53. Bhatia MS, Munjal S. Prevalence of depression in people living with HIV/ AIDS undergoing ART and factors associated with it. J Clin Diagnostic Res. 2014:8:WC01-4.

54. Nanni MG, Caruso R, Mitchell AJ, Meggiolaro E, Grassi L. Depression in HIV infected patients: a review. Curr Psychiatry Rep. 2015;17:530.

55. Pappin M, Wouters E, Booysen FLR. Anxiety and depression amongst patients enrolled in a public sector antiretroviral treatment programme in South Africa: a cross-sectional study. BMC Public Health. 2012;12:244. 
56. Tesfaw G, Ayano G, Awoke T, Assefa D, Birhanu Z, Miheretie G, et al. Prevalence and correlates of depression and anxiety among patients with HIV on-follow up at alert hospital, Addis Ababa, Ethiopia. BMC Psychiatry. 2016;16:368.

57. Kamen C, Arganbright J, Kienitz E, Weller M, Khaylis A, Shenkman T, et al. HIV-related stigma: implications for symptoms of anxiety and depression among Malawian women. African J AIDS Res. 2015;14:67-73.

58. Sherr L, Clucas C, Harding R, Sibley E, Catalan J. HIV and depression - a systematic review of interventions. Psychol Health Med. 2011;16:493-527.

59. Nanni MG, Caruso R, Mitchell AJ, Meggiolaro E, Grassi L. Depression in HIV infected patients: a review. Curr Psychiatry Rep. 2015;17:1-11.

60. Szanto K, Gildengers A, Mulsant BH, Brown G, Alexopoulos GS, Reynolds CF. Identification of suicidal ideation and prevention of suicidal behaviour in the elderly. Drugs Aging. 2002;19:11-24.

61. Ceccon RF, Meneghel SN, Hirakata VN. Women with HIV: gender violence and suicidal ideation. Rev Saude Publica. 2014;48:758-65.

62. Indonesian Health Ministry. Laporan perkembangan HIV AIDS \& infeksi menular seksual tahun 2018. Kementerian Kesehatan Republik Indonesia; 2018. p. 1-158. http://siha.depkes.go.id/portal/files_upload/Laporan_Triwulan_IV_2018.pdf. Accessed 20 Oct 2019.

63. Onyebueke GC, Okwaraji FE. Depression and suicide risk among HIV positive individuals attending an out patient HIV/Aids clinic of a Nigerian tertiary health institution. J Psychiatry. 2015;18:1-8.

64. Preston $\mathrm{SH}$. The changing relation between mortality and level of economic development. Popul Stud (NY). 1975;29:231-48.

65. Tanaka C, Tuliao MTR, Tanaka E, Yamashita T, Matsuo H. A qualitative study on the stigma experienced by people with mental health problems and epilepsy in the Philippines. BMC Psychiatry. 2018;18:325.

66. Nachega JB, Morroni C, Zuniga JM, Sherer R, Beyrer C, Solomon S, et al. HIVrelated stigma, isolation, discrimination, and serostatus disclosure: a global survey of 2035 HIV-infected adults. J Int Assoc Phys AIDS Care. 2012;11:172-8,

67. Amanor-Boadu S, Hipolito MS, Rai N, McLean CK, Flanagan K, Hamilton FT, et al. Poor CD4 count is a predictor of untreated depression in human immunodeficiency virus-positive African-Americans. World J Psychiatry. 2016;6:128-35.

68. McIntosh RC, Seay JS, Antoni MH, Schneiderman N. Cognitive vulnerability for depression in HIV. J Affect Disord. 2013;150:908-15.

69. Wulunggono W, Yunihastuti E, Shatri H, Wahyudi ER, Ophinni Y. Frailty among HIV-1 infected adults under antiretroviral therapy in Indonesia. Curr HIV Res. 2019;17:204-13.

70. Kaharuza FM, Bunnell R, Moss S, Purcell DW, Bikaako-Kajura W, Wamai N, et al. Depression and CD4 cell count among persons with HIV infection in Uganda. AIDS Behav. 2006;10(SUPPL. 7):105-11.

71. Subbaraman R, Chaguturu SK, Mayer KH, Flanigan TP, Kumarasamy N. Adverse effects of highly active antiretroviral therapy in developing countries. Clin Infect Dis. 2007;45:1093-101.

72. Arendt G, de Nocker D, von Giesen H-J, Nolting T. Neuropsychiatric side effects of efavirenz therapy. Expert Opin Drug Saf. 2007;6:147-54.

73. Fumaz CR, Muñoz-Moreno JA, Moltó J, Negredo E, Ferrer MJ, Sirera G, et al. Long-term neuropsychiatric disorders on efavirenz-based approaches: quality of life, psychologic issues, and adherence. J Acquir Immune Defic Syndr. 2005;38:560-5.

74. Mothapo K, Schellekens A, Crevel R, Keuter M, Grintjes-Huisman K, Koopmans $P$, et al. Improvement of depression and anxiety after discontinuation of long-term efavirenz treatment. CNS Neurol Disord - Drug Targets. 2015;14:811-8.

75. Cavalcante GIT, Capistrano VLM, Cavalcante FSD, Vasconcelos SMM, MacDo DS, Sousa FCF, et al. Implications of efavirenz for neuropsychiatry: a review. Int J Neurosci. 2010;120:739-45.

76. Apostolova N, Funes HA, Blas-Garcia A, Galindo MJ, Alvarez A, Esplugues JV. Efavirenz and the CNS: what we already know and questions that need to be answered. J Antimicrob Chemother. 2015;70:2693-708.

77. Dabaghzadeh F, Jabbari F, Khalili H, Abbasian L. Associated factors of suicidal thoughts in HIV-positive individuals. Iran J Psychiatry. 2015;10:185-91.

78. Chang JL, Tsai AC, Musinguzi N, Haberer JE, Boum Y, Muzoora C, et al. Depression and suicidal ideation among HIV-infected adults receiving efavirenz versus nevirapine in Uganda: a prospective cohort study. Ann Intern Med. 2018;169:146-55.

79. de Beaudrap P, Etard J-F, Gueye FN, Gueye M, Landman R, Girard P-M, et al. Long-term efficacy and tolerance of efavirenz- and nevirapine-containing regimens in adult HIV type 1 Senegalese patients. AIDS Res Hum Retrovir. 2008;24:753-60.

80. Olley BO, Seedat S, Nei DG, Stein DJ. Predictors of major depression in recently diagnosed patients with HIV/AIDS in South Africa. AIDS Patient Care STDs. 2004;18:481-7.

81. Amiya RM, Poudel KC, Poudel-Tandukar K, Pandey BD, Jimba M. Perceived family support, depression, and suicidal ideation among people living with HIV/AIDS: a cross-sectional study in the Kathmandu Valley, Nepal. PLoS One. 2014:9:e90959.

\section{Publisher's Note}

Springer Nature remains neutral with regard to jurisdictional claims in published maps and institutional affiliations.
Ready to submit your research? Choose BMC and benefit from:

- fast, convenient online submission

- thorough peer review by experienced researchers in your field

- rapid publication on acceptance

- support for research data, including large and complex data types

- gold Open Access which fosters wider collaboration and increased citations

- maximum visibility for your research: over $100 \mathrm{M}$ website views per year

At BMC, research is always in progress.

Learn more biomedcentral.com/submissions 